\title{
The Enlightenment of Shenzhen Science and Technology Financial Research to Ankang from the Perspective of Innovation Drive
}

\author{
Zhou Yinan \\ International Business School, Shaanxi Normal University \\ Xi'an, Shaanxi 710119 \\ 359321584@qq.com
}

\begin{abstract}
The National Science and Technology Innovation Plan, published in August of 2016, clearly proposed to perfect the financial system that supports scientific and technological innovation, which provides a new opportunity for the development of science and technology finance in China. We can draw the inspiration of Ankang city through studying the status of the development of science and technology finance in Shenzhen Hi-tech Zone. First, we need the government to formulate policies and integrate financial institutions. Second, public and market finance funds should be used to promote the stability of development of science and technology finance. Finally, its own endowments should be fully used, which would take the special way of science and technology financial belonging to Ankang itself.
\end{abstract}

Keywords-Driven by Innovation; Technology Finance; Model of Achievement Transformation

\section{INTRODUCTION}

For a long time, we all rely on the production, consumption, and integration of labor, land, capital, and the natural environment to develop the economy. And this type of economic development has achieved certain results in the early stages of development. However, with the speed of development, the drawbacks gradually appear and even hinder economic development to a certain extent. Therefore, the country proposes to drive innovation instead of production factors. Innovation-driven development is dependent on innovation, so that production factors are highly integrated, agglomerated, and sustainable in creating wealth, thus driving economic and social health and steadily moving forward. China's "Thirteenth Five-Year Plan" has brought innovationdriven ideas to an unprecedented level. Particular emphasis is placed on the important role of financial support for innovation-driven development. And in the "13th Five-Year Plan for National Science and Technology Innovation Plan" released in August 2016, it is clearly proposed that a financial system that supports scientific and technological innovation should be clearly established, which provides a new opportunity for the development of science and technology finance in China[1].
The economic crisis has caused the global economy to remain sluggish, and developed countries have stepped up investment in technological innovation, accelerated the development of high-tech industries, and explore new economic growth points and strategic commanding heights. In August 2014, General Secretary Xi Jinping emphasized at the 7th meeting of the Central Financial Leadership Group that the implementation of innovation-driven development strategy is to promote comprehensive innovation with science and technology as the core. Adhere to the direction of demand orientation and industrialization, adhere to the dominant position of enterprises in innovation, and give play to the decisive role of the market in resource allocation and the advantages of the socialist system. Strengthen the contribution of scientific and technological progress to economic growth, form a new source of growth and promote sustainable and healthy economic development.

\section{THE STATUS OF THE DEVELOPMENT OF SCIENCE AND TECHNOLOGY FINANCE IN SHENZHEN HI-TECH ZONE}

Shenzhen High-tech Zone was built in September 1996. It is one of the six pilot parks of the state "building a world-class high-tech park" and is a "National Intellectual Property Pilot Park" and "National High-tech Industry Standardization Demonstration Zone". Relying on the Pearl River Delta, Shenzhen is close to Hong Kong, a financial center, and can use domestic and overseas financial resources [2].

Shenzhen has given full play to its institutional advantages of pioneering and experimenting, and has been bold in innovating and actively exploring, continuously deepening the reform of the science and technology system, giving full play to the decisive role of the market in allocating innovation resources, innovating the input methods of financial science and technology funds, and effectively guiding financial resources into continuous technological innovation [3]. The establishment of a diversified technology financing system covering the entire chain of innovation, including bank credit, securities market, venture capital, guarantee funds and government venture capital guidance funds, has gradually emerged as a road of development of science and technology finance with Shenzhen characteristics. 


\section{A. The government supports social capital to technological innovation}

In order to give full play to the financial capital guidance function and leverage effect, Shenzhen City issued the "Shenzhen Science and Technology R\&D Capital Investment Reform Plan" to comprehensively mobilize various resources in the capital market, such as banking and insurance, to invest in scientific and technological innovation, and put governments, enterprises, and banks in the organic combination will form a financing mechanism with a government-dominated status and a positive interaction between enterprises and financial institutions. Financial institutions provide more diversified financing channels for the development of small and mediumsized technology companies.

One is to use bank-level corporate subsidies to subsidize banking resources. Shenzhen Finance made a one-time arrangement of RMB 400 million as the principal of the entrusted loan, depositing it into a government-affiliated bank with a time deposit, and the cooperating bank would use 6-10 times the amount of the entrusted fund. Second, it will use technology insurance premiums to fund the insurance industry to leverage resources. The Shenzhen Municipal Government allocates 10 million yuan each year to provide premium subsidies for high-tech enterprises, strategic emerging industries, and software companies that have already insured high-tech insurance, and the highest funding ratio is $50 \%$ of the actual premiums paid by the company. Third, the angel investment guidance project was used to finance social investment. For enterprises that receive angel investment, the Shenzhen government gives $2 \%$ of the investment subsidies.

\section{B. Encourage institutions such as banks and insurance to organize financing support for science and technology enterprises}

In order to solve the problems of the traditional operating modes of banks and other institutions that are not suitable for the development of science and technology finance, Shenzhen has boldly explored and put forward the requirements of "three transformations," namely, the specialized forms of business organization, differentiated credit management models and long-term assessment incentive mechanisms. . At the same time, we will open a green channel for access to science and technology finance, encourage banks to set up a science and technology finance division, and set up or renovate branch branch science and technology branches.

The first is to encourage innovative loan methods. Banks are encouraged to implement new loan models such as IP pledge loans, equity pledged loans, intangible asset mortgage loans, accounts receivable pledged loans, and rental income pledged loans. The second is to support the political and monetary cooperation to set up a technology bank union. In 2014, the Shenzhen Science and Technology Innovation Committee and the Shenzhen Branch of China Construction Bank jointly initiated the establishment of the Technology Bank Alliance to provide comprehensive high-tech companies with comprehensive financial services ranging from financing to financial intelligence.

\section{The ENLIGHTENMENT OF SHENZHEN SCIENCE AND TECHNOLOGY FINANCE DEVELOPMENT TO ANKANG}

The Ankang Hi-tech Zone started in 2000. After the transformation from the former Ankang Bio-Tech Industrial Park and the Shaanxi Ankang Industrial Park, the provincial government approved the upgrade to a provincial-level hightech development zone on December 31, 2009, and enjoys the municipal economic management power [4]. Ankang Hi-tech Zone is committed to building China's selenium-enriched foods, China's plant extracts, Shaanxi's new materials 'three bases'; efforts to form the four centers of industry, research and development, business, logistics; focus on the development of selenium-enriched food, Qinba medicine, new Materials, energy conservation and environmental protection and characteristic services 'Five industries'; focus on improving the core area of the 'one body and two wings' plan, the carrying capacity of the integrated urban new area, the gathering area of modern science and technology industries, the commanding heights of the industrial park system, and the incubator of companies, technologies and talents. The "six functions" of the demonstration zone for the coordinated development of urban and rural areas."

\section{A. The government formulates policies and integrates financial institutions}

Ankang is a concentrated contiguous area in the Qinba Mountains. The economic development has lagged behind the surrounding provinces and cities for a long time. The financial industry also has its fatal shortcomings: the system is not perfect, the products are not abundant, the service functions are poor, and the capital market has not yet developed. In addition, the approval and supervision of local financing institutions such as small loan companies, pawn shops, and financing guarantee companies are scattered in different government departments. It is difficult to form a joint force, and financial risks can easily be formed. To this end, Ankang City has established a leading group for financial work, established a joint financial conference system, and strengthened government management, service, and coordination functions[5-6].Through the formulation of a local financial development master plan, the development of financing institutions will be promoted and the construction of a local credit system will be promoted. We will promote financial reform and development as a matter of great importance to the overall economic development, support the financial industry as a key industry, implement unified planning, unified supervision and unified coordination, and guide the healthy development of the financial industry. 


\section{B. Capital investment in public and market finance to promote stable development of technology finance}

The first step in the construction of science and technology finance will inevitably require the accumulation of initial capital. Using the initial capital to enter the science and technology financial system will be the starting point for the internal circulation of the science and technology financial system. The extensive existence of market borders may cause market failures in scientific and technological innovation activities, and the accumulation of funds in the science and technology financial system will inevitably require government-led funds as start-up funds, thereby guaranteeing scientific and technological innovation activities that are decisive for macroeconomic and social development.

The basic characteristics of technological innovation are the long cycle and large investment. In the process of technological innovation, technology transformation, productization, and industrialization, they all show a lack of funds. The most basic function of the S\&T financial system is to solve the financial problems in the process of technological innovation and industrial upgrading. The government gives full play to its financial capital guidance function and leverage effect. In the science and technology financial system that is mainly guided by the government and supplemented by market-oriented operations, the government, banks, and enterprises are rationally integrated, leveraging on the diversification of financial service entities [7]. The science and technology innovation subjects at different stages of scientific and technological innovation provide an effective fund allocation method.

\section{Make full use of their talents to develop characteristic technology finance}

The selenium-enriched resource endowments in the Ankang region have certain advantages both inside and outside the province. Selenium-enriched resources development should be said to be the most distinctive and well-established industry in Ankang. In recent years, Ankang City, relying on resources rich in selenium, has been actively developing seleniumenriched industries in the process of seeking breakthrough development and has achieved remarkable results. However, whether it is the degree of development and utilization of resources, or the scale and benefits of the industry are preliminary, it is far from turning huge resource advantages into economic advantages. How to give full play to Ankang's advantages of selenium-rich resources, increase the technological content and added value of selenium-enriched foods, expand the development of selenium-enriched food industry, strengthen the modern industrial system of seleniumenriched foods, accelerate the development of seleniumenriched food industry, and urgently need to strengthen Technological innovation work. Therefore, establishing a sound scientific and technological support system for the selenium-enriched food industry is of great significance for improving the development level and benefits of the seleniumenriched food industry and promoting the economic development of Ankang.
Guide the local colleges and universities, relevant scientific and technological units and scientific and technical personnel of Ankang to actively carry out research and development work on the development of selenium-enriched resources. We must closely follow the reality of the selenium-rich characteristics, the development of selenium-rich resources, and the development of selenium-enriched food industry in Ankang City, clarify the direction of scientific research, establish scientific research topics, actively apply for scientific research projects at all levels, and strengthen research and development. Through the reforms and adjustments of the organization methods, input methods, capital flows, and program categories at all levels, the enthusiasm of enterprises, universities, and research institutes will be mobilized in three aspects, and the scientific and technological resources will be guided to gather in the form of a combination of production, education and research. Shifting from research and development focused on universities and research institutes to building a technological innovation system that focuses on companies as the mainstay, market orientation, and integration of production, learning and research, and guides companies to become the main body of technological innovation; shifts their focus from focusing on micro-projects to strengthening on scientific and technological innovations. The macro management, more emphasis on innovative projects and innovative talent, innovation team. Through the guidance of scientific and technological plans at all levels, the main body of enterprise innovation will be strengthened, so that universities and research institutes will be more proactive in carrying out technological innovation cooperation with enterprises in the form of joint undertaking of projects, joint construction of bases, and interactive human resources exchanges, and strengthen universities and scientific research institutions. The ability of the service industry.

Ankang has rich natural endowments, especially seleniumenriched products. It should vigorously develop the seleniumrich industry, provide preferential loans to small and medium enterprises of Ankang related to selenium-rich enterprises, and should vigorously promote the introduction of investment projects to attract foreign companies to take root in the wellbeing. Make full use of the prominent geographic advantages of the geometric centers in the three major economic zones of Xi'an, Chongqing, and Wuhan. Ankang's existing pharmaceutical research institutes, agricultural research institutes, and selenium-enriched laboratories and other advantageous resources should be used as the basis to invest funds to support Ankang's scientific research institutions and research institutes and to advance the scientific and technological achievements of universities, research institutes and enterprises in Xi'an. The results of industry, academia, and research were transformed into Ankang to form their own unique scientific and technological industries. 


\section{CONCLUSION}

Compared with Shenzhen, the innovation model of Shaanxi Province belongs to the path of "result transformation", that is, the innovation activities of universities and research institutions as the starting point, and the innovation activities of the economic system are stimulated by the gradual evolution of laboratory results to application links. Shenzhen's innovation belongs to the "demand-pulling" path model, that is, the starting point of innovation activities is the enterprise, the environment is the market, and the enterprise product forms the demand for technology in the development process and transmits this demand to the upstream of the innovation chain. The mode of production, education, and research cooperation achieves the goal of innovation. These two different innovation models lead to different innovation paths. Different innovation paths determine the degree of integration between innovation and market economy, and different degrees of integration will determine different innovation performances.

\section{REFERENCES}

[1] Yu Lu. Dong Xiaoyuan, Director, Institute of Economics, Shenzhen Academy of Social Sciences: science and Technology Finance is the key to Shenzhen's Innovation $[N]$. Shenzhen Business Daily (Shenzhen Business Daily).

[2] On National Day. Science and Technology Finance [M]. Economic Management Press.

[3] Chen Xi. Path Choice of Innovation-Driven Development Strategy [J]. Economic problems are in 2013.

[4] Duan Yongbing. To insert financial wings for scientific and technological innovation-Shenzhen financial support for scientific and technological innovation practices for our province [N]. HAINAN TODAYA 20171D.

[5] Shen Zhe. Shenzhen high tech cooperation with the government to promote technological and financial development $[\mathrm{N}]$. Science and technology daily, 2015 (008).

[6] Cao Hao, you Jianxin, Lu Rui, Chen Haiyang. Empirical research on China's science and technology financial development index [J]. Chinese management science, 2011, 19 (3).

[7] Zhong Ruo. The key to Shenzhen's financial development is to encourage continuous innovation and development of SMEs and new industries [N]. focuses on 2011 (2). 